\title{
Article
}

\section{In Situ Observations of the Atomistic Mechanisms of Ni Catalyzed Low Temperature Graphene Growth}

Laerte L Patera, Cristina Africh, Robert S Weatherup, Raoul Blume, Sunil Bhardwaj, Carla CastellarinCudia, Axel Knop-Gericke, Robert Schloegl, Giovanni Comelli, Stephan Hofmann, and Cinzia Cepek

ACS Nano, Just Accepted Manuscript • DOI: 10.1021/nn402927q • Publication Date (Web): 08 Aug 2013

Downloaded from http://pubs.acs.org on August 8, 2013

\section{Just Accepted}

"Just Accepted" manuscripts have been peer-reviewed and accepted for publication. They are posted online prior to technical editing, formatting for publication and author proofing. The American Chemical Society provides "Just Accepted" as a free service to the research community to expedite the dissemination of scientific material as soon as possible after acceptance. "Just Accepted" manuscripts appear in full in PDF format accompanied by an HTML abstract. "Just Accepted" manuscripts have been fully peer reviewed, but should not be considered the official version of record. They are accessible to all readers and citable by the Digital Object Identifier (DOI®). "Just Accepted" is an optional service offered to authors. Therefore, the "Just Accepted" Web site may not include all articles that will be published in the journal. After a manuscript is technically edited and formatted, it will be removed from the "Just Accepted" Web site and published as an ASAP article. Note that technical editing may introduce minor changes to the manuscript text and/or graphics which could affect content, and all legal disclaimers and ethical guidelines that apply to the journal pertain. ACS cannot be held responsible for errors or consequences arising from the use of information contained in these "Just Accepted" manuscripts. 


\title{
In Situ Observations of the Atomistic Mechanisms of $\mathrm{Ni}$
}

\section{Catalyzed Low Temperature Graphene Growth}

\author{
Laerte L. Patera ${ }^{1,2}$, Cristina Africh ${ }^{1, *}$, Robert S. Weatherup ${ }^{3}$, Raoul Blume $^{4}$, Sunil Bhardwaj ${ }^{5}$, Carla Castellarin-Cudia ${ }^{1}$, \\ Axel Knop-Gericke ${ }^{6}$, Robert Schloegl ${ }^{6}$, Giovanni Comelli, ${ }^{1,2}$, Stephan Hofmann ${ }^{3,}{ }^{,}$Cinzia Cepek $^{1}$ \\ ${ }^{1}$ CNR-IOM, Laboratorio TASC, Strada Statale 14, Km.163.5 I-34149 Trieste, Italy \\ ${ }^{2}$ Physics Dept. and CENMAT, University of Trieste, via A. Valerio 2, I-34127 Trieste, Italy \\ ${ }^{3}$ Dept. of Engineering, University of Cambridge, Cambridge CB3 OFA, UK \\ ${ }^{4}$ Helmholtz-Zentrum Berlin fuer Materialien und Energie GmbH, Division Solar Energy Research, Berlin, Germany \\ ${ }^{5}$ Sincrotrone Trieste S.C.p.A., Strada Statale 14, Km 163.5, I-34149 Trieste, Italy \\ ${ }^{6}$ Fritz Haber Institute, D-14195 Berlin-Dahlem, Germany
}

\begin{abstract}
The key atomistic mechanisms of graphene formation on $\mathrm{Ni}$ for technologically relevant hydrocarbon exposures below $600^{\circ} \mathrm{C}$ are directly revealed via complementary in situ scanning tunneling microscopy and Xray photoelectron spectroscopy. For clean $\mathrm{Ni}(111)$ below $500^{\circ} \mathrm{C}$, two different surface carbide $\left(\mathrm{Ni}_{2} \mathrm{C}\right)$ conversion mechanisms are dominant which both yield epitaxial graphene, whereas above $500^{\circ} \mathrm{C}$ graphene predominantly grows directly on $\mathrm{Ni}(111)$ via replacement mechanisms leading to embedded epitaxial and/or rotated graphene domains. Upon cooling, additional carbon structures form exclusively underneath rotated graphene domains. The dominant graphene growth mechanism also critically depends on the near-surface carbon concentration
\end{abstract}


and hence is intimately linked to the full history of the catalyst and all possible sources of contamination. The detailed XPS fingerprinting of these processes allows a direct link to high pressure XPS measurements of a wide range of growth conditions, including polycrystalline $\mathrm{Ni}$ catalysts and recipes commonly used in industrial reactors for graphene and carbon nanotube CVD. This enables an unambiguous and consistent interpretation of prior literature and an assessment of how the quality/structure of as-grown carbon nanostructures relates to the growth modes.

KEYWORDS: Graphene, Chemical vapor deposition (CVD), Ni, surface carbide, Scanning Tunneling Microscopy (STM), X-ray photoelectron spectroscopy (XPS)

CORRESPONDING AUTHORS:

*africh@iom.cnr.it, sh315@cam.ac.uk 
The route towards the commercial exploitation of graphene's unique properties hinges entirely on the development of adequate graphene growth and integration technology. ${ }^{1}$ Chemical vapor deposition (CVD) is widely seen as the most versatile and promising technique for this. Despite recent progress in achieving graphene CVD over large areas, ${ }^{2,3}$ the growth process and underlying mechanisms have yet to be fully understood. This limits further process and material optimization, and key open questions regarding industrial materials development remain to be addressed. The formation of high quality graphene at reasonably low temperatures largely relies on the use of a catalyst. $\mathrm{Ni}$ is a common catalyst choice, both for graphene and carbon nanotube (CNT) CVD, ${ }^{4-7}$ due to the ease of dehydrogenation of typical hydrocarbon precursors on its surface, followed by the effective formation of a graphitic lattice. In particular, the atomic structure of monolayer graphene (MLG) on $\mathrm{Ni}(111)$ is thereby a widely studied model system, based on the close lattice match and related promise for commensurate epitaxial growth of structurally homogeneous graphene. ${ }^{8-10}$ The relatively high carbon solubility of $\mathrm{Ni}$ and resulting carbon dissolution and bulk reservoir effect, combined with the vast parameter space of catalytic CVD and the related importance of growth kinetics, ${ }^{11,12}$ however, make growth control and the unambiguous identification of the key growth mechanisms challenging. ${ }^{13}$ Graphene uniformity and layer control over large areas remain very difficult to achieve on $\mathrm{Ni}$. Additional complexity arises from reconstructions that $\mathrm{Ni}$ surfaces may undergo upon carbon adsorption, e.g. $\mathrm{Ni}(111)$ showing a $\mathrm{Ni}_{2} \mathrm{C}$ surface phase. ${ }^{14}$ Recent literature shows a coexistence of graphene and $\mathrm{Ni}_{2} \mathrm{C}$ on $\mathrm{Ni}(111)$ and suggests that graphene growth below $460^{\circ} \mathrm{C}$ occurs via an in-plane conversion mechanism, ${ }^{15}$ in contrast to graphene growth via carbon attachment directly on $\mathrm{Ni}(111) .{ }^{16-18}$ This in-plane conversion has been suggested to impose a $3^{\circ}$ rotation between the graphene and underlying $\mathrm{Ni}(111) \cdot{ }^{15}$ Rotated MLG on Ni(111), which is unexpected given the widely reported $1 \times 1$ epitaxial match, has also been linked to graphene growth on top of residual $\mathrm{Ni}_{2} \mathrm{C}$ domains ${ }^{19}$ or reported to nucleate directly above a critical growth temperature of $650^{\circ} \mathrm{C} .{ }^{20}$ Notably, most data and literature to date is limited by characterization at a post-growth stage. Hence, despite the atomic structure

\section{Page $\mathbf{3}$ of $\mathbf{3 1}$}


of graphene on $\mathrm{Ni}$ having been investigated for decades, there remains limited direct evidence of the atomistic details involved in the growth process.

Here, we directly study the atomistic mechanisms of graphene formation on Ni via complementary scanning tunneling microscopy (STM) and X-ray photoelectron spectroscopy (XPS), both performed in situ under in operando conditions and supported by systematic ex situ CVD calibrations. We focus on technologically relevant hydrocarbon exposures below $600^{\circ} \mathrm{C}$ for which our STM data shows a range of co-existing, competing atomic-scale growth mechanisms even for a supposedly simple $\mathrm{Ni}(111)$ model surface. We report detailed XPS fingerprints representative of these processes, which allow a direct link to high pressure XPS measurements of a wide range of growth conditions, including polycrystalline $\mathrm{Ni}$ catalysts and recipes commonly used in industrial reactors for graphene and CNT CVD. ${ }^{5,21,22}$ Our intention is thereby to capture the entire complexity of the CVD process in order to enable an unambiguous and consistent interpretation of prior literature from different scientific communities and an assessment of how the quality/structure of as-grown carbon nanostructures relates to the growth modes. We find that the relative balance among the atomistic processes, i.e. the dominant graphene growth mechanism, thereby depends not only on conventional CVD parameters such as temperature and pressure but also on the full-history dependent/adventitious near-surface level of carbon in $\mathrm{Ni}$, similar to recent reports for other catalyst metals and CNT growth. ${ }^{23,24}$

Our in situ data shows that a clean $\mathrm{Ni}(111)$ surface exposed below $500^{\circ} \mathrm{C}$ predominantly shows an initial $\mathrm{Ni}_{2} \mathrm{C}$ reconstruction, which converts into MLG either via an in-plane mechanism, similar to what has been previously proposed, ${ }^{15}$ or via a novel two-layer mechanism. We show that the carbide conversion mechanisms thereby always result in epitaxial MLG, i.e. $\mathrm{Ni}_{2} \mathrm{C}$ is not a source of graphene grain rotation. Above $500^{\circ} \mathrm{C}$, graphene dominantly grows directly on clean $\mathrm{Ni}(111)$ via replacement of $\mathrm{Ni}$ surface atoms, which leads to embedded epitaxial and/or rotated MLG domains. Again, we observe no abrupt transition between mechanisms, i.e. no critical transition temperature, rather the relative abundance of rotated MLG domains increases with Page $\mathbf{4}$ of $\mathbf{3 1}$ 
temperature, indicative of a kinetic selection process. In contrast, given a carbon "contaminated" Ni subsurface prior to the hydrocarbon exposure, we observe no $\mathrm{Ni}_{2} \mathrm{C}$ reconstruction even for the lower temperature range, but observe for instance that epitaxial MLG growth directly on Ni via the expansion of graphene seeds can predominate across the whole temperature range. Across all experiments, graphene growth occurs during exposure (or on annealing) at fixed temperatures. Carbon precipitation upon cooling is minor, consistent with our previously reported kinetic model ${ }^{11}$ and the low temperature conditions, but it is noteworthy that if it does occur it is observed exclusively underneath rotated MLG domains, resulting in the formation of $\mathrm{Ni}_{2} \mathrm{C}$. This consistently resolves ambiguity in previous post-growth data interpretation ${ }^{19}$ and agrees well with reported bilayer graphene formation under rotated MLG upon cooling from $650^{\circ} \mathrm{C}^{20}$ We discuss how our high pressure XPS data allows us to generalize these findings to realistic, scalable graphene growth processes as well as being relevant to CVD of CNTs and other nanocarbons.

\section{RESULTS AND DISCUSSION}

As a representative model system, we focus initially on graphene growth on $\mathrm{Ni}(111)$ in the $400-600^{\circ} \mathrm{C}$ temperature range and adopt a simple one-step CVD process, whereby the sample is heated and cooled in vacuum, and exposed to an undiluted hydrocarbon precursor (see Methods). We use different base vacuum conditions, both ultra-high vacuum (UHV, i.e. base pressure $<10^{-9} \mathrm{mbar}$ ), and high vacuum (base pressure: $10^{-8}$ $10^{-6} \mathrm{mbar}$ ), to bridge a range of CVD conditions. In order to take into account the exposure history and carbon contamination level in the $\mathrm{Ni}$ layers closest to the surface, we differentiate between clean and carboncontaminated Ni subsurfaces. The $\mathrm{Ni}(111)$ substrates we refer to as having a "clean subsurface" are prepared by multiple cleaning cycles (see Methods) after which no carbon signatures are observed during extended UHV annealing ( $30 \mathrm{~min}$ in $\mathrm{p}<2 \times 10^{-10} \mathrm{mbar}$ ) at the growth temperature in both STM and photoemission experiments. The substrates referred to as having a "carbon contaminated subsurface" are samples that even Page 5 of 31 
after cleaning show carbon surface signatures (prior to any hydrocarbon exposure) upon heating to the growth temperature. All STM experiments have been repeated several times on different regions of the sample using the same growth conditions to ensure the observed processes are statistically representative. Specifically, we performed about 20 experiments at $410^{\circ} \mathrm{C}<\mathrm{T}<440^{\circ} \mathrm{C}, 20$ experiments at $500^{\circ} \mathrm{C}<\mathrm{T}<530^{\circ} \mathrm{C}$, and 5 experiments at $550^{\circ} \mathrm{C}<\mathrm{T}<600^{\circ} \mathrm{C}$, for both clean and carbon contaminated Ni subsurfaces. In the following we focus on the key growth mechanisms for the given conditions, and show representative sequences of STM images in each case. We emphasise though that all the revealed atomic-scale mechanisms occur simultaneously, and that it is their relative balance that changes with conditions.

\section{Clean subsurface}

\section{Growth at $400-500^{\circ} \mathrm{C}$}

Figure 1 shows in situ STM images of the Ni catalyst surface during $\mathrm{C}_{2} \mathrm{H}_{4}$ exposure at $420^{\circ} \mathrm{C}$, representative of different stages of graphene formation during the exposure phase. Figure 1a shows a step edge on the initially clean $\mathrm{Ni}(111)$ surface which appears fuzzy due to the fast dynamics of attaching/detaching metal atoms at elevated temperature. We cannot directly resolve Ni mass transport on the terraces, as it occurs on a time scale too short to be followed with our STM scan speed (which requires adatom residence times in surface sites to be $>10^{-4} \mathrm{~s}$ ), as typical for self-diffusion processes on metallic surfaces. ${ }^{25}$ After a few minutes of $\mathrm{C}_{2} \mathrm{H}_{4}$ exposure, an almost complete layer of $\mathrm{Ni}_{2} \mathrm{C}$ forms at the surface (Fig. 1b). The structure of surface nickel carbide, with $\mathrm{Ni}_{2} \mathrm{C}$ stoichiometry, has been investigated and described in previous literature, ${ }^{14,19}$ and is characterized by a peculiar atomic arrangement and related LEED pattern, which we used as fingerprints to interpret our images. In particular, the adsorption of $\mathrm{C}$ atoms on $\mathrm{Ni}(111)$ induces a surface stress, which is relaxed by a displacement of $\mathrm{Ni}$ atoms and by a removal of about 13 atom\% of the first metal layer. ${ }^{14}$ The $\mathrm{Ni}$ 
and $\mathrm{C}$ atoms thereby rearrange into a V39R16. $1^{\circ} \times \sqrt{ } 39 \mathrm{R} 16.1^{\circ}$ overstructure, with an almost square $\sim 5 \times 5 \AA^{2}$ cell. In this structure, the Ni surface undergoes a "clock" reconstruction, which is reached by squares of Ni atoms rotating clock- and anti-clockwise. This ordered surface carbide $\left(\mathrm{Ni}_{2} \mathrm{C}\right)$ can be easily recognized in STM by a superstructure characterized by stripes with a periodicity of $\sim 16.5 \AA .^{14,19}$ Indeed, our STM images of the intermediate structure that forms before graphene upon hydrocarbon exposure, shown in Fig. 1b, exhibit both stripe periodicity and atomic scale arrangement in perfect agreement with refs. ${ }^{14}$ and ${ }^{19}$, as well as the same LEED pattern, which confirms our assignment.

After several minutes of further continuous exposure, the $\mathrm{Ni}_{2} \mathrm{C}$ starts to convert into MLG (Fig. 1C), a process which proceeds over a time scale of a few hours at the given conditions, until a complete graphene monolayer is produced (Fig. 1d). The atomic scale structure of this graphene layer (see inset Fig. 1d) is an ordered honeycomb lattice of $C$ atoms with two inequivalent adsorption sites, separated by a distance equal to the lattice constant of graphene. As previously shown for both experimental and simulated images, ${ }^{26-28}$ the inequivalent adsorption sites of the MLG C atoms, strongly interacting with the Ni substrate, appear as a triangular close-packed array instead of a honeycomb network. The enlargement of such triangular closepacked areas in our STM movies upon further hydrocarbon exposure corroborates their interpretation as MLG. Again, our assignment is consistently confirmed by LEED and XPS (Fig. 3), as well as by UPS (see Supporting Information). The lack of a moiré pattern indicates that (i) the mismatch between the $\mathrm{Ni}(111)$ substrate and the graphene overlayer is minimal, as expected based on their very close lattice match $(\sim 1 \%),{ }^{29}$ and (ii) that the MLG is not rotated relative to the $\mathrm{Ni}(111)$ surface. The absence of a rotation angle is also confirmed by the LEED pattern of the final surface (see below). The as-formed graphene is thus epitaxial. We estimate a defect density of $\sim 1-2 \%$, calculated as the fraction of missing $C$ atoms at the bright spots in the STM images, which we suggest are due to the presence of substitutional $\mathrm{Ni}$ atoms.

Page $\mathbf{7}$ of $\mathbf{3 1}$ 
We find the $\mathrm{Ni}_{2} \mathrm{C}$ conversion to be the principal graphene growth route on clean $\mathrm{Ni}$ for the low temperature range probed $\left(400-500^{\circ} \mathrm{C}\right)$. Figure 2 is representative of the behavior observed across our experiments, and identifies two different mechanisms by which this conversion proceeds (see corresponding movies in Supporting Information): an in-plane conversion mechanism and a distinct two-layer mechanism. Figure 2a shows STM data representative of the in-plane conversion mechanism. The sequence of images shows a fixed area of the surface scanned at a frame rate of $\sim 2$ images $/$ min during $\mathrm{C}_{2} \mathrm{H}_{4}\left(2 \times 10^{-7} \mathrm{mbar}\right)$ exposure at $420^{\circ} \mathrm{C}$. It is clearly seen that the MLG (right hand side, Fig. 2a) expands at the expense of the initial $\mathrm{Ni}_{2} \mathrm{C}$ structure (on the left, Fig. 2a), whereby the MLG is adsorbed on the same $\mathrm{Ni}$ layer supporting the $\mathrm{Ni}_{2} \mathrm{C}$ (see Supporting Information for detailed STM analysis). Figure 2(b) schematically highlights the details of this in-plane conversion mechanism: $\mathrm{Ni}$ atoms are ejected from the reconstructed $\mathrm{Ni}_{2} \mathrm{C}$ layer and quickly diffuse away due to their high mobility; concurrently the surface carbon coverage increases and a hexagonal graphitic network forms. As discussed in the following, based on previous literature and supported by our findings on contaminated substrates (see below), we propose that the additional carbon atoms, in this case, reach the carbide/graphene interface from below the surface and thereby displace and eject Ni surface atoms.

The MLG growth occurs during exposure at fixed temperature, i.e. the widely held assumption that graphene growth on $\mathrm{Ni}$ is solely based on carbon precipitation upon cooling ${ }^{6,7}$ is incorrect. During exposure, hydrocarbon molecules adsorb on the $\mathrm{Ni}$ surface, dissociate, and $\mathrm{C}$ atoms dissolve into the $\mathrm{Ni}$. $\mathrm{Ni}_{2} \mathrm{C}$ nucleation and conversion requires the build-up of a sufficient carbon concentration at the Ni surface, which relates to the observed incubation times. In our previous work, ${ }^{11}$ we established a kinetic model whereby graphene growth proceeds by the build-up of a local carbon supersaturation at the Ni surface, which depends on the flux balance between carbon reaching and leaving the catalyst surface. Carbon can arrive via the gas phase (on the clean portion of the surface or through defects on already carbon-covered areas) or via segregation from the catalyst bulk, whilst it can leave via diffusion into the catalyst bulk. This general kinetic model is applicable to every kind 
of substrate, both for the $\mathrm{Ni}_{2} \mathrm{C}$ formation and conversion, as well as for graphene formation directly on $\mathrm{Ni}$. It is interesting to note that in model systems the $\mathrm{Ni}_{2} \mathrm{C}$ layer has been reported to passivate the Ni catalyst surface (at least at step edges). ${ }^{30}$ This can impede carbon precursor dissociation in an analogous manner to graphene coverage. ${ }^{11}$ The more complete this passivation, the more the carbon flux to the Ni surface/interface will be dominated by isothermal segregation from the Ni bulk. This may account for the notable delay we observe in graphene nucleation following $\mathrm{Ni}_{2} \mathrm{C}$ formation.

The general scenario of carbon dissolution and re-segregation to the surface to form graphene by the observed in-plane $\mathrm{Ni}_{2} \mathrm{C}$ conversion mechanism is similar to what has been proposed by Lahiri et al., ${ }^{15}$ and is also consistent with their DFT results, showing that the process in which $\mathrm{Ni}$ atoms at the carbide/graphene interface are removed from $\mathrm{Ni}_{2} \mathrm{C}$ and replaced by carbon atoms from the bulk, is exothermic. ${ }^{15}$ This previous post-growth data, however, showed a $3^{\circ}$ rotation between the graphene and underlying $\mathrm{Ni}(111)$ which was suggested to be due to the preference of the growing graphene to form a coincidence structure with the surface carbide at their $1 \mathrm{D}$ interface. ${ }^{15}$ Our in situ data clearly shows that in all cases $\mathrm{Ni}_{2} \mathrm{C}$ conversion leads to only epitaxial graphene formation and we further show that inconsistencies in literature regarding the formation of rotated domains due to $\mathrm{Ni}_{2} \mathrm{C}$ are likely to arise from ambiguity in the interpretation of post-growth data $a^{15,19}$ as discussed in detail below.

Figure $2 \mathrm{c}$ shows STM data representative of a different, two-layer $\mathrm{Ni}_{2} \mathrm{C}$ conversion mechanism (see Supporting Information for full STM movie). While the graphene island labeled $\mathrm{Gr}^{(1)}$ grows via the in-plane conversion mechanism described above at the edges of the $\mathrm{Ni}_{2} \mathrm{C}$ region, the $\mathrm{MLG}$ domain labeled $\mathrm{Gr}^{(2)}$ appears to expand on (and exclusively on) the same $\mathrm{Ni}_{2} \mathrm{C}$ region. Our height analysis in the Supporting Information clearly shows that $\mathrm{Gr}^{(2)}$ grows on a metal atomic layer, probably formed from $\mathrm{Ni}$ atoms which were initially part of the $\mathrm{Ni}_{2} \mathrm{C}$ along with additional $\mathrm{Ni}$ atoms fast diffusing on the surface (see Supporting Information), rather than as an overlayer on the $\mathrm{Ni}_{2} \mathrm{C}$ as previously suggested, ${ }^{19}$ or as a bilayer graphene region. This last statement Page $\mathbf{9}$ of $\mathbf{3 1}$ 
is also confirmed by ex situ photoemission results, which only indicate the presence of epitaxial MLG for the same final surface. The proposed conversion process leading to the formation of the $\mathrm{Gr}^{(2)}$ graphene domain is schematically outlined in Fig $2 \mathrm{~d}$ : carbon atoms in the $\mathrm{Ni}_{2} \mathrm{C}$ layer are promoted one layer higher, whilst the $\mathrm{Ni}$ surface deconstructs back to $(1 \times 1)$, requiring mass transport to supply the additional Ni. Further carbon atoms arrive, and a graphene island forms. The reaction/conversion front of this two-layer mechanism proceeds at $\sim 0.8 \AA / \mathrm{s}$, much faster than the reaction front of the in-plane conversion $(\sim 0.15 \AA / \mathrm{s}$, values extracted from movie S2). For the in-plane conversion, the topmost $\mathrm{Ni}$ atoms corresponding to $87 \%$ of a $\mathrm{Ni}(111)$ layer have to be locally removed whilst for the two-layer conversion, additional $\mathrm{Ni}$ atoms corresponding to only $13 \%$ of a $\mathrm{Ni}(111)$ layer are required to reconstruct the top-most metal layer. We note that the difference in graphene growth rate between the mechanisms may relate to this difference in the required Ni mass transport. In the temperature range considered here, however, we always find the most common growth process to be the inplane conversion mechanism, indicating a kinetic selection dominated by a lower nucleation barrier for this process. Again, the $\mathrm{Ni}$ mass transport involved in both of these $\mathrm{Ni}_{2} \mathrm{C}$ conversion mechanisms cannot be resolved with the available STM time resolution. It is important to note, that none of our post-growth measurements reveal the formation of further carbon structures underneath the epitaxial MLG on $\mathrm{Ni}(111)$ following cooling.

\section{Chemical identification of the $\mathrm{C}$ species}

We further investigate the carbide conversion mechanisms using complementary in situ and ex situ XPS to provide a record and fingerprint of the chemical evolution of the $\mathrm{Ni}(111)$ surface during graphene formation over a much larger area (from 0.01 to $\sim 1 \mathrm{~mm}^{2}$ spot size range). We focus first on obtaining XPS fingerprints for each of the surface structures observed with STM, by reproducing the same experimental conditions used for 
STM in a conventional UHV XPS system (see Methods). Figure 3 shows the C1s core levels (left), and the corresponding LEED patterns (right) acquired at RT of clean $\mathrm{Ni}(111)$ (Fig. 3a), $\mathrm{Ni}_{2} \mathrm{C}$ (Fig. 3b), and graphene covered $\mathrm{Ni}(111)$ (Fig. 3c-d) surfaces. The LEED provides a direct link with the structures observed in STM, as a morphological check to confirm that the expected phase is produced across the surface. We follow the same deconvolution of the XPS C1s spectra as in Ref. ${ }^{5}$, using the same four key components, $C_{A}(283.2 e V), C_{D i s}$ (283.8eV), $\mathrm{C}_{\mathrm{Gr}}(284.4 \mathrm{eV})$, and $\mathrm{C}_{\mathrm{B}}(284.8 \mathrm{eV})$.

The $\mathrm{C} 1 \mathrm{~s}$ spectrum of the graphene covered $\mathrm{Ni}(111)$ surface in Figure $3 \mathrm{c}$ shows a dominant $\mathrm{C}_{\mathrm{B}}$ component, $\sim 72 \%$ of the total $\mathrm{C} 1 \mathrm{~s}$ intensity, with the $\mathrm{C}_{\mathrm{Dis}}$ and $\mathrm{C}_{\mathrm{Gr}}$ contributing $\sim 12 \%$ and $\sim 15 \%$ respectively, whilst the intensity of $C_{A}$ is negligible $(<1 \%)$. LEED shows the hexagonal pattern expected for epitaxial graphene on $\mathrm{Ni}(111)$, and we thereby assign $\mathrm{C}_{B}$ to epitaxial graphene. We note that the $\mathrm{C}_{B}$ peak position corresponds also to carbon atoms with different bonding configurations, ${ }^{31,32}$ the presence of which can be excluded here based on our STM observations. $C_{\text {Dis }}$ has previously been identified as interstitial carbon dissolved in to the Ni forming a Ni-rich solid solution. ${ }^{5,33} \mathrm{C}_{\mathrm{Gr}}$, has the same energy as for pristine $\mathrm{HOPG},{ }^{34}$ and is thus assigned to weakly coupled and non-defective graphene layers, which may include rotated graphene, additional graphene layers, or graphene decoupled from the Ni surface e.g. by intercalation of adspecies. ${ }^{35}$ During STM experiments few rotated graphene islands have been observed, and we thus assign the weak $C_{G r}$ peak to rotated graphene for the low pressure $\left(<10^{-6} \mathrm{mbar}\right)$ and low temperature $\left(<500^{\circ} \mathrm{C}\right)$ conditions considered here.

For the $\mathrm{Ni}_{2} \mathrm{C}$ covered $\mathrm{Ni}(111)$ surface (Fig. $\left.3 b\right)$, the most intense peak is $\mathrm{C}_{\mathrm{A}}(71 \%)$, with some $\mathrm{C}_{B}(18 \%$ corresponding to a coverage of $\sim 5 \%$ of the $\mathrm{Ni}(111)$ surface), a small percent of $C_{\mathrm{Dis}}(\sim 7 \%)$, and negligible $\mathrm{C}_{\mathrm{Gr}}$ (4\%) (last two components not visible in figure scale). The presence of $\mathrm{Ni}_{2} \mathrm{C}$ on the $\mathrm{Ni}(111)$ surface is confirmed by the appearance of its typical LEED pattern ${ }^{36}$ as shown in Figure 3. Our analysis also indicates that the intensity ratio between the $C_{B}$ peak of the graphene covered $\mathrm{Ni}(111)$ surface and the $C_{A}$ peak of the $\mathrm{Ni}_{2} \mathrm{C}$ covered $\mathrm{Ni}(111)$ surface is $4.0: 1$, which within experimental error corresponds to the ratio of the carbon atomic Page 11 of 31 
densities of graphene and $\mathrm{Ni}_{2} \mathrm{C}(4.7: 1) .{ }^{14}$ However we also expect that carbon bonded at Ni surface sites, not necessarily forming a long-range ordered structure, would show a component of similar binding energy resulting from a similar charge transfer from $\mathrm{Ni}$ to embedded $\mathrm{C}$ atoms. This broader assignment of $\mathrm{C}_{\mathrm{A}}$ could account for previous observations of a $\mathrm{C}_{\mathrm{A}}$ peak under conditions where $\mathrm{Ni}_{2} \mathrm{C}$ may be unstable, ${ }^{5,21}$ and will be addressed in a further publication. Given the direct correspondence between our XPS and STM results, for the conditions used herein on $\mathrm{Ni}(111)$ surfaces, we conclude that $C_{A}$ relates to $\mathrm{Ni}_{2} \mathrm{C}$, while $C_{B}$ relates to epitaxial graphene.

Figure 4 shows the time-resolved chemical evolution of the C1s spectra for the $\mathrm{Ni}(111)$ surface during graphene growth, measured using synchrotron radiation (see Methods). We observe the appearance of the same four, principal components as identified earlier $\left(C_{A}, C_{D i s}, C_{G r}\right.$ and $\left.C_{B}\right)$. On $C_{2} H_{4}$ exposure, $C_{A}$ and a weak $C_{D i s}$ signal initially appear, followed by the emergence of the $C_{B}$ and a smaller $C_{G r}$ component. $C_{B}$ grows with continuing hydrocarbon exposure becoming the dominant species, accompanied by a strong reduction in the $C_{A}$ peak intensity, until the $C_{B}$ peak intensity almost saturates (the exposure was stopped before reaching complete monolayer coverage). $C_{G r}$ also grows concurrently with $C_{B}$ but its intensity remains $<10 \%$ that of the dominant $C_{B}$ peak. This peak evolution allows us to generalize our findings for a wider range of vacuum conditions (both base and exposure pressures): as soon as the hydrocarbon exposure starts, carbon dissociates on the bare $\mathrm{Ni}(111)$ surface, dissolves in to the $\mathrm{Ni}$ leading to an increase in the level of dissolved carbon in the subsurface, and the $\mathrm{Ni}_{2} \mathrm{C}$ phase forms across the surface. In this case the induction time is shorter than for STM experiments $\left(\sim 1^{\prime}\right.$ vs. $\left.\sim 10^{\prime}\right)$, as expected due to the higher $\mathrm{C}_{2} \mathrm{H}_{4}$ pressure $(\sim 3$ times $) .{ }^{11}$ With continuing hydrocarbon exposure, the $\mathrm{Ni}_{2} \mathrm{C}$ gradually transforms into epitaxial graphene until almost complete coverage with an epitaxial graphene monolayer is achieved (see Supporting Information for details on carbide to graphene conversion growth rate). The presence of the small $C_{G r}$ peak that accompanies $C_{B}$ indicates that a small proportion of the surface is covered with rotated graphene. We emphasize that for our previous 
observations on polycrystalline films, the same four XP components can be consistently fitted and the order of peak appearance remains the same. ${ }^{5,21}$ This is also the case for graphene growth from different carbon sources, including gaseous hydrocarbons $\left(\mathrm{C}_{2} \mathrm{H}_{2}, \mathrm{C}_{2} \mathrm{H}_{4}\right.$, and $\left.\mathrm{C}_{6} \mathrm{H}_{6}\right)$, as well as solid carbon sources (tetrahedral amorphous carbon). This highlights that the detailed growth mechanisms observed using STM on Ni(111) surfaces during $\mathrm{C}_{2} \mathrm{H}_{4}$ exposure are also important for technologically relevant polycrystalline catalysts and a number of different carbon sources, in spite of the added complexities of multiple surface orientations and differences in the carbon supply. Our detailed interpretation of XPS signatures allows us to bridge the so-called pressure and materials gap, ${ }^{37}$ i.e. allows us to generalize our findings to realistic, scalable graphene growth processes as well as being relevant to CVD of carbon nanotubes (CNT) and other nanocarbons.

\section{Growth at $500-600^{\circ} \mathrm{C}$}

Figure 5 shows representative STM images of graphene growth on clean $\mathrm{Ni}(111)$ above $500^{\circ} \mathrm{C} . \mathrm{Ni}_{2} \mathrm{C}$ formation during the first growth stages is progressively reduced, although not completely suppressed, as the exposure temperature is increased above $500^{\circ} \mathrm{C}$, and a different dominant graphene growth route sets in, as revealed by the STM images, whereby graphene grows directly on $\mathrm{Ni}(111)$ via $\mathrm{Ni}$ replacement mechanisms. After nucleation, graphene islands grow embedded into the Ni surface, preferentially elongated in a close-packed $\mathrm{Ni}(111)$ direction (see dark stripe in Fig. 5a, and detailed STM height analysis in Supporting Information). The final complete monolayer includes not only epitaxial regions, but also moiré domains, as shown in Fig 5b. The moiré domains are due to a rotation of the graphene layer with respect to the underlying $\mathrm{Ni}(111)$ surface (see Supporting Information). The balance between epitaxial and rotated domains in the final MLG surface shows a strong dependence on the growth temperature: at higher temperatures, rotated domains are increasingly present in STM images, and, at the same time, arches of extra spots appear in the LEED pattern, centered at $\sim 20^{\circ}$, as shown by the arrows in Figure 3. Growth of rotated MLG directly on $\mathrm{Ni}(111)$ is consistent with a Page 13 of 31 
previous LEED/LEEM study, ${ }^{20}$ albeit therein a critical growth temperature of $650^{\circ} \mathrm{C}$ was assumed. Indeed, DFT studies predict only a small energy difference between stable epitaxial graphene configurations and less interacting configurations with a lack of preferred C-Ni registry. ${ }^{38}$ We therefore attribute the increasing coverage of rotated graphene for increasing temperature to kinetic effects. We have not captured here the very first nucleation stages, but the sequence of STM images in Fig. 5d (STM movie S3, available in Supporting Information) illustrates how embedded graphene regions grow. Elongated MLG islands expand on the same terrace, one towards the other, at $\sim 1 \AA / s$, progressively reducing the width of the bare Ni surface in between, until only a line of point defects remains. This growth mechanism can be rationalized as schematically outlined in Figure 5e: when a first graphene nucleus is present, additional $\mathrm{C}$ atoms segregate to the surface at its borders, facilitating the ejection of $\mathrm{Ni}$ atoms, and attach to the graphene island edges, thus replacing surface $\mathrm{Ni}$ atoms. In this way, the anchoring points are shifted and the MLG island expands. A similar growth by the removal of metal atoms at graphene edges has also been observed on $\mathrm{Rh}(111)^{24}$ and $\mathrm{Ru}(0001),{ }^{39,40}$ albeit as a more minor growth mechanism. The dominant growth mechanism for these surfaces is typically carbon attachment to the edges of graphene islands atop the metal. This difference in dominant growth mechanism may relate to the significantly higher carbon solubility of $\mathrm{Ni}$ compared to $\mathrm{Rh}$ and $\mathrm{Ru}^{8,41}$ which may facilitate $\mathrm{Ni}$ atom ejection. It is noteworthy that we have also observed a mechanism here by which MLG islands expand directly atop $\mathrm{Ni}(111)$, i.e. where the graphene is not embedded. However, as outlined below, we find this mechanism to be dominant only in the case of a carbon contaminated subsurface. A previous LEEM study, ${ }^{18}$ suggested that graphene islands grow by $\mathrm{C}$ addition to "free" graphene edges upon prolonged exposure of $\mathrm{Ni}(111)$ to ethylene at $550^{\circ} \mathrm{C}$, i.e. comparable conditions to our embedded growth on clean $\mathrm{Ni}$ in the $500-600^{\circ} \mathrm{C}$ range. This apparent disparity may be associated with the huge mass transport involved in the embedded growth mechanism. This Ni mass transport, which we observe preceding the embedded graphene growth front, may relate to the surface diffusion processes previously suggested based on LEEM measurements. ${ }^{18}$ Indeed, when imaging clean Ni terraces by STM during graphene growth, we sometimes observed a sudden Page 14 of 31 
change in the morphology, with new Ni layers forming above the previously imaged topmost layer, on which the growth of embedded graphene then proceeds. Notably, for lower growth temperatures, the present STM and previous LEEM investigations agree in the identification of a process that involves carbide conversion.

Upon cooling of the MLG covered surface to room temperature, a different STM contrast appears in some regions (roughly 30-50\%) of the rotated graphene (Fig. 5c). This different contrast was previously observed, and attributed, based on detailed analysis, to the presence of $\mathrm{Ni}_{2} \mathrm{C}$ islands underneath the rotated MLG. ${ }^{19}$ Our in situ data here clearly shows that this structure results from the precipitation of carbon upon cooling. This agrees well with our ex situ XPS data (Figure 3d), acquired on the same MLG covered surface as imaged with STM, which confirms the presence of both rotated graphene and carbide after cooling to RT. Detailed XPS data analysis shows that the major contribution to the $\mathrm{C} 1 \mathrm{~s}$ spectrum comes from the $\mathrm{C}_{\mathrm{Gr}}$ component (surface coverage: $\sim 87 \%$ ), assigned to rotated domains, with a small percentage of epitaxial graphene $C_{B}$ (surface coverage: $\sim 13 \%)$, and negligible $C_{D I S}(<1 \%)$. Given that our STM results reveal that the carbide is formed upon cooling only below rotated graphene, XPS data analysis (see Supporting Information) suggests $\sim 37 \%$ of the rotated graphene has carbide underneath, in agreement with our STM measurements. The observed lower binding energy of the rotated graphene overlayer $\left(C_{G r}\right)$ is almost the same as for weakly interacting graphene layers. ${ }^{42,43}$ This suggests that the bonding with the substrate is characterized by a lower charge transfer from the $\mathrm{Ni}(111)$ than in the case of an epitaxial overlayer, due to the lack of a direct Ni-top-C interaction, which is responsible for most of the charge transfer in MLG. ${ }^{44}$ This consistently resolves ambiguity in previous postgrowth data interpretation ${ }^{19}$ and agrees well with reported bilayer graphene formation under rotated MLG upon cooling from $650^{\circ} \mathrm{C}^{20}$

\title{
Carbon-contaminated subsurface: growth at $400-600^{\circ} \mathrm{C}$
}

\author{
Page $\mathbf{1 5}$ of $\mathbf{3 1}$
}


The mechanisms established above all refer to conventional CVD parameters such as temperature and pressure, which can be carefully controlled. Figures 6 and 7, however, show that the dominant graphene growth mechanism critically depends also on the near-surface carbon concentration which is much more difficult to control as it is intimately linked to the full history of the catalyst and all possible sources of contamination. We previously highlighted how minor, routinely present levels of carbon contamination can significantly influence CNT growth kinetics. ${ }^{23}$ Here we show that the graphene growth scenario can change completely if the $\mathrm{Ni}(111)$ substrate does not undergo a complete cleaning procedure and some residual carbon contamination is present in the subsurface, a case which we refer to as "carbon-contaminated subsurface". For this case, even though the Ni surface appears clean at RT in XPS and LEED, with only some small carbide islands present in STM images, as soon as the temperature is increased to the growth temperature, prior to exposure, we observe the formation of graphene seeds at the Ni surface, both at Ni steps (Fig. 6a), and as small islands on top of metal terraces (Fig. 6b). Once at the growth temperature, in UHV conditions, the seeds expand even without gas exposure, fed by $\mathrm{C}$ atoms from the subsurface reservoir, leading to a complete, mainly epitaxial MLG coverage over the whole temperature range investigated (Fig. 6c), without any intermediate carbide phase. This picture is confirmed by all our XPS (Fig. 7), STM and LEED (not shown) experiments. The expansion of the graphene seeds thereby occurs on top of the Ni substrate, by $\mathrm{C}$ atom addition to graphene edges, as shown by the selected frames in Fig. 6d (see corresponding Supplementary Movie S4) and schematically outlined in Fig. 6e. Such graphene growth in UHV without hydrocarbon exposure is clear evidence of the capability of subsurface $C$ to diffuse to the surface and form graphene. This further corroborates the growth models on clean Ni described in the previous sections. Our investigations of seeded graphene growth are ongoing and the related details are beyond the scope of this paper. We find it important here, however, to highlight the significance of developing a strategy to control all growth parameters, in particular the substrate contamination, as it has so far been widely neglected across the literature. We highlight that consideration of 
the influence of such minor carbon contamination is also highly relevant when comparing UHV data to more realistic CVD conditions used in industrial reactors.

\title{
CONCLUSIONS
}

We have directly revealed and characterized a number of competing atomistic mechanisms of graphene formation on $\mathrm{Ni}$ for technologically relevant low temperature CVD via complementary STM and XPS, both performed in situ under in operando conditions and supported by systematic ex situ CVD calibrations. Figure 8 schematically summarizes the dominant growth routes with respect to the CVD conditions and the initial level of subsurface carbon. For clean $\mathrm{Ni}(111)$, below $500^{\circ} \mathrm{C}$ the formation of an intermediate, structural surface carbide $\left(\mathrm{Ni}_{2} \mathrm{C}\right)$ is favored, which converts into epitaxial graphene. Above $500^{\circ} \mathrm{C}$, graphene predominantly grows directly on $\mathrm{Ni}(111)$ via replacement mechanisms leading to embedded epitaxial and/or rotated graphene domains. Surface carbide formation is thereby not the source of graphene grain rotation, rather rotated graphene domains nucleate directly on $\mathrm{Ni}(111)$ at sufficiently high temperatures and their increased relative abundance (compared to epitaxial domains) with increasing temperature is kinetically determined. We show that the dominant graphene growth mechanism critically depends not only on conventional CVD parameters but also on the near-surface carbon concentration which is much more difficult to control, as it is intimately linked to the full history of the catalyst and all possible sources of contamination. Given a carbon-contaminated surface prior to hydrocarbon exposure, for instance, epitaxial MLG growth directly on Ni via the expansion of such seeds by $\mathrm{C}$ addition at their edges above the substrate predominates across the whole temperature range probed.

Importantly, in all the explored conditions, graphene grows isothermally up to a complete monolayer. Upon cooling further changes can occur. In particular, on $\mathrm{Ni}(111)$ we observed the formation of $\mathrm{Ni}_{2} \mathrm{C}$ regions

\author{
Page 17 of 31
}


underneath rotated graphene domains and on bare $\mathrm{Ni}(111)$, but not underneath epitaxial graphene. Given that not only $\mathrm{Ni}_{2} \mathrm{C}$ but also an additional graphene layer would grow only at the interface between the $\mathrm{Ni}$ and the existing graphene layer, i.e. in contact with the $\mathrm{Ni}$, as also observed for $\mathrm{CNT}$ growth, ${ }^{4,45}$ this suggests that the strong interaction of epitaxial MLG on $\mathrm{Ni}(111)$ significantly increases the energy barrier for further graphene layer nucleation.

Further to the data reported here, our previous high-pressure XPS measurements of growth on polycrystalline $\mathrm{Ni}\left(550 \mathrm{~nm}\right.$ films and $25 \mu \mathrm{m}$ foils), ${ }^{5,21}$ performed across a broad range of hydrocarbon pressures, allow us to generalize our findings. In particular, we have observed a general trend for a reduction in the $C_{A}$ peak intensity with increasing growth temperature, and a related shift in the $C_{B}$ to $C_{G r}$ ratio towards the latter. This is consistent with the shift in the balance of growth mechanisms from graphene growth by transformation of an intermediate surface carbide towards the direct growth of rotated graphene (Fig. 8).

As known from literature and our prior work, for higher CVD exposure pressures self-limitation to monolayer graphene coverage can not necessarily be assumed, and particularly for $\mathrm{Ni}$ it is very challenging at high pressures to achieve graphene uniformity and layer control. ${ }^{6,7,21}$ Given the possibility of much higher carbon supersaturations at the Ni surface, we suggest based on our data here (Fig. 8) that higher precursor exposure pressures favor the nucleation of rotated graphene domains, lowering the nucleation barriers for multi-layer graphene by decoupling the graphene from the Ni surface. Indeed, recent post-growth STM data indicates a prevalence of multilayer graphene consisting of rotated domains during atmospheric pressure CVD on polycrystalline $\mathrm{Ni}^{46} \mathrm{~A}$ less strongly interacting graphene layer, such as rotated MLG, may also facilitate graphene growth across the grain boundaries of polycrystalline catalysts, as previously shown for polycrystalline $\mathrm{Ru}^{47}$

We believe that the understanding of the atomic scale growth mechanisms established here is highly relevant for the controlled graphene growth over a broad range of conditions and, in particular with regards to Page 18 of 31 
the question of how quality/structure relates to the underlying growth modes, is of general relevance to all related catalytically grown carbon nanostructures.

\title{
METHODS
}

We performed in situ STM under in operando conditions to monitor the structural evolution of the (111) surface of a Ni single crystal ( $1 \mathrm{~mm}$ thick) during exposure to $\mathrm{C}_{2} \mathrm{H}_{4}\left(10^{-7} \mathrm{mbar}\right.$ pressure range) at $400-600^{\circ} \mathrm{C}$. We combine this with both ex situ and in situ XPS and UPS experiments in a conventional UHV chamber, and with in situ, time-resolved XPS measurements with synchrotron radiation on $\mathrm{Ni}(111)$ during $\mathrm{C}_{2} \mathrm{H}_{4}\left(10^{-6} \mathrm{mbar}\right.$ pressure range) exposures. Before exposure, the $\mathrm{Ni}(111)$ surface was carefully cleaned, as confirmed by a clear hexagonal LEED pattern and by the absence of any $C$ structure in room temperature (RT) STM images, and the absence of any C peak in XPS spectra. In all experiments, the sample temperature was measured with a K-type thermocouple spot-welded on the Ni single crystal.

STM experiments have been performed in a UHV (base pressure: $\sim 10^{-10} \mathrm{mbar}$ ) chamber equipped with standard preparation/characterization facilities (sputter gun, heating stage, gas line, LEED) and a commercial Omicron VT-STM, modified to yield atomic resolution measurements at high temperature up to $600^{\circ} \mathrm{C}$ and in reactive environment, with a frame-rate of $1-2$ images/min. The $\mathrm{Ni}(111)$ sample was cleaned by repeated cycles of $\mathrm{Ar}^{+}$sputtering $(15 \mathrm{~min}, 2 \mathrm{KeV})$ and flash annealing $\left(600^{\circ} \mathrm{C}\right)$ in $\mathrm{UHV}$. The cleaning cycles were stopped when the sample did not show any $\mathrm{C}$ structure at $\mathrm{RT}$, such as $\mathrm{Ni}_{2} \mathrm{C}$ islands at the step edges, suggesting a very low carbon contamination in the single crystal. Growth studies were performed by backfilling the chamber with $\mathrm{C}_{2} \mathrm{H}_{4}\left(2 \times 10^{-7} \mathrm{mbar}-\right.$ to be locally corrected for an estimated screening factor of 5 in the area shadowed by the $\operatorname{tip}^{48}$ ) while acquiring a series of consecutive STM images at frame rate of $\sim 2$ images $/ \mathrm{min}$.

\author{
Page 19 of 31
}


The UHV (base pressure: $\sim 10^{-10} \mathrm{mbar}$ ) in situ and ex situ photoemission spectra acquired on $\mathrm{Ni}(111)$ were measured at RT in normal emission geometry, using a hemispherical electron energy analyzer, and a conventional Mg Ka X-ray source (hv: $1253.6 \mathrm{eV}$ ) and a He lamp (hv: 40.8eV). The overall energy resolution for the XPS and UPS spectra were, respectively $\sim 0.8 \mathrm{eV}$ and $\sim 0.2 \mathrm{eV} .$. The overall energy resolution for the XPS spectra was $\sim 0.8 \mathrm{eV}$. The XPS binding energies scale was calibrated by setting the $\mathrm{Ni} 2 p_{3 / 2}$ peak of the clean $\mathrm{Ni}(111)$ at $852.6 \mathrm{eV}$.

In situ, time-resolved high-resolution XPS experiments were performed at the ISISS beamline of the Fritz Haber Institute located at the BESSY II synchrotron facility in Berlin. The high-pressure setup consists mainly of a reaction cell (base pressure $\sim 10^{-7} \mathrm{mbar}$ ) attached to a set of differentially pumped electrostatic lenses and a differential-pumped analyzer (Phoibos 150, SPECS GmbH), as described elsewhere. ${ }^{49}$ Samples were pretreated by oxidation $\left(p\left(\mathrm{O}_{2}\right)=1 \times 10^{-4} \mathrm{mbar}, 30 \mathrm{~s}\right)$ and reduction $\left(p\left(\mathrm{H}_{2}\right)=1 \times 10^{-4} \mathrm{mbar}, 3 \mathrm{~min}\right)$ at $\sim 600^{\circ} \mathrm{C}$ to leave a clean $\mathrm{Ni}$ surface with no detectable $\mathrm{C}$ species in the C1s spectra, prior to hydrocarbon exposures. All spectra are collected in normal emission geometry at photon energies of $425 \mathrm{eV}$ (surface sensitive: $\lambda_{\mathrm{e}} \approx 7 \AA$, where $\lambda_{\mathrm{e}}$ is the inelastic mean free path of the photoelectrons at $\sim 425 \mathrm{eV}$ kinetic energy in solids), with a spot size of $80 \mu \mathrm{m} \times$ $150 \mu \mathrm{m}$. Time signatures are relative to when the $\mathrm{C}_{2} \mathrm{H}_{4}$ valve is opened and spectral acquisition begins.

All C $1 s$ spectra were analyzed by performing a non-linear mean square fit of the data, using four DoniachŠùnjić components superimposed on a Shirley background. The asymmetries and Lorentzian linewidths were extracted from the high-resolution spectra, by fixing the asymmetries of the $C_{D i s}$ component to zero, while leaving as free parameters in the fit procedure those of $C_{A}, C_{G r}$ and $C_{B}$. The resulting asymmetries of the $C_{G r}$ and $C_{B}$ components were the same, 0.144 , while the $C_{A}$ asymmetry, determined from the deconvolution of the pure carbide phase, was 0.089 . The intrinsic Lorentzian linewidth $\mathrm{G}$ was $\sim 0.24 \mathrm{eV}$, compatible with literature results in carbon-based materials. The low-resolution spectra were analyzed using the so-obtained asymmetries and Lorentzian width values.

\author{
Page 20 of $\mathbf{3 1}$
}


Acknowledgments

L.L.P. acknowledges funding from Area di Ricerca Scientifica e Tecnologica of Trieste and from MIUR through Progetto Strategico NFFA. C.A. acknowledges support from CNR through the ESF FANAS project NOMCIS. C.A. and C.C. acknowledge financial support from MIUR (PRIN 2010-2011 № 2010N3T9M4). S.B. acknowledges funding from ICTP TRIL program. S.H. acknowledges funding from ERC grant InsituNANO (n²79342). R.S.W. acknowledges funding from EPSRC (Doctoral training award), and the Nano Science \& Technology Doctoral Training Centre Cambridge (NanoDTC). The help of C. Dri and F. Esch (design) and P. Bertoch and F. Salvador (manufacturing) in the realization of the high temperature STM sample holder is gratefully acknowledged. We acknowledge the Helmholtz-Zentrum-Berlin Electron storage ring BESSY II for provision of synchrotron radiation at the ISISS beamline and we thank the BESSY staff for continuous support of our experiments.

\section{Supporting Information Available:}

STM movie files, detailed STM image analysis and details of XPS analysis. This material is available free of charge via the Internet at http://pubs.acs.org. 
Figure Captions:

Figure 1. STM images acquired at $420^{\circ} \mathrm{C}$ at different growth stages upon $\mathrm{C}_{2} \mathrm{H}_{4}$ exposure of clean $\mathrm{Ni}(111)$ : (a) Clean $\mathrm{Ni}(111)$ step edge; (b) Nickel carbide $\left(\mathrm{Ni}_{2} \mathrm{C}\right)$ domains on $\mathrm{Ni}(111)$. Inset: atomic resolution image of the area in the dotted square. The almost square $5 \times 5 \AA^{2}$ unit cell is marked in green; (c) Domain boundary between $\mathrm{Ni}_{2} \mathrm{C}$ (left) and graphene (right), during conversion; (d) Defected graphene on Ni(111). Inset: Atomically resolved image of graphene. The inequivalent $\mathrm{C}$ atoms of a graphene ring are marked in blue and green. The orientation of the crystallographic directions of our sample were identified in atomic resolution images of the clean $\mathrm{Ni}(111)$ surface acquired at RT (not shown), and were kept constant in all experiments since the crystal has never been removed nor rotated on the sample holder. Scanning parameters: (a) $V_{b}=-2 V, l_{t}=0.5 n A$; $(b) V_{b}=-$ $10 \mathrm{mV}, \mathrm{I}_{\mathrm{t}}=1 \mathrm{nA} ;$ (c) $\mathrm{V}_{\mathrm{b}}=-100 \mathrm{mV}, \mathrm{I}_{\mathrm{t}}=0.1 \mathrm{nA} ;$ (d) $\mathrm{V}_{\mathrm{b}}=-50 \mathrm{mV}, \mathrm{l}_{\mathrm{t}}=0.7 \mathrm{nA}$ (insets: $\mathrm{V}_{\mathrm{b}}=-10 \mathrm{mV}, \mathrm{I}_{\mathrm{t}}=1 \mathrm{nA}(\mathrm{b}) ; \mathrm{V}_{\mathrm{b}}=-300 \mathrm{mV}$, $\left.\mathrm{I}_{\mathrm{t}}=0.5 \mathrm{nA}(\mathrm{d})\right)$.

Figure 2. STM images and schematic models of Nickel carbide to graphene conversion: (a-b) In-plane conversion (see corresponding Supplementary Movie S1). In the STM images, the region on the left is covered by $\mathrm{Ni}_{2} \mathrm{C}$, the region on the right by graphene. The red dot marks the position of a fixed defect on the surface. $\mathrm{Ni}$ atoms are ejected when additional $\mathrm{C}$ atoms reach the surface from the bulk to extend the graphene region. (cd) Two-layer conversion (see corresponding Supplementary Movie S2). In the STM images, while the graphene region labeled $\mathrm{Gr}^{(1)}$ grows from $\mathrm{Ni}_{2} \mathrm{C}$ via in-plane conversion, the graphene island labeled $\mathrm{Gr}^{(2)}$ grows on the same carbide domain by a two-layer conversion mechanism. Here additional $\mathrm{C}$ atoms reach the graphene/carbide interface, the Ni layer deconstructs to $(1 \times 1)$, and the graphene island expands. In the lower left corner of the first STM image in sequence, $\mathrm{Ni}_{2} \mathrm{C}$ stripes are highlighted by a different image contrast. In both (a) and (c): $\mathrm{T}=420^{\circ} \mathrm{C}, \mathrm{p}\left(\mathrm{C}_{2} \mathrm{H}_{4}\right)=2 \times 10^{-7} \mathrm{mbar}$. Time between displayed frames: $\sim 120 \mathrm{~s}(\mathrm{a})$ and $\sim 90 \mathrm{~s}$ (c).

\section{Page 22 of 31}


Scanning parameters: (a) $V_{b}=-100 \mathrm{mV}, \mathrm{I}_{\mathrm{t}}=0.1 \mathrm{nA}$, (c) $\mathrm{V}_{\mathrm{b}}=-250 \mathrm{mV}, \mathrm{l}_{\mathrm{t}}=0.5 \mathrm{nA}$. In the schematic models grey/lightblue/green/purple balls represent $\mathrm{Ni}$ /dissolved $\mathrm{C} /$ carbidic $\mathrm{C} /$ graphenic $\mathrm{C}$ atoms.

Figure 3. C 1s XPS spectra (left), and corresponding negative of the LEED patterns (right) of (a) clean $\mathrm{Ni(111),(b)}$ carbide, (c) epitaxial graphene, (d) rotated graphene phases. The photoemission spectra are acquired at RT in normal emission geometry using a conventional $\mathrm{Mg} \mathrm{K}_{\mathrm{a}} \mathrm{X}$-ray source at an overall energy resolution of $\sim 0.8 \mathrm{eV}$. Superimposed to the $\mathrm{C} 1 \mathrm{~s}$ experimental data (dots) are the fitting results (light grey) together with the Shirley background (dotted line) and the four Doniach-Šunjić $C_{A}$ (green), $C_{B}$ (purple), $C_{G r}$ (blue) and $C_{D i s}$ (light-blue) components (see text for further details). All LEED are acquired at RT ( $\left.E_{p}: \sim 70 \mathrm{eV}\right)$. The arrows in the carbide LEED image indicate the position of two $(1 \times 1)$ spots, while the arrows in the rotated graphene LEED image indicate the extra spots of the moiré pattern.

Figure 4. Time-resolved in situ high resolution XPS C1s core level spectra during low pressure CVD on a "clean subsurface" $\mathrm{Ni}(111)$ single crystal [base pressure $\sim 10^{-7} \mathrm{mbar}, \mathrm{T}=400^{\circ} \mathrm{C}, \mathrm{p}\left(\mathrm{C}_{2} \mathrm{H}_{4}\right)=6 \times 10^{-7} \mathrm{mbar}$ ]. Time $=0$ is relative to when the $\mathrm{C}_{2} \mathrm{H}_{4}$ valve is opened and spectral acquisition begins, however exposure pressure is not instantaneously reached. All spectra are collected in normal emission geometry at photon energies of $435 \mathrm{eV}$ (surface sensitive; $\lambda_{\text {escape }} \approx 7 \AA$ ) with a spectral resolution of $\sim 0.3 \mathrm{eV}$. Superimposed to the $\mathrm{C} 1 \mathrm{~s}$ experimental data (dots) are the fitting results (light grey) together with the Shirley background (dotted line) and the four Doniach-Šunjić $C_{A}$ (green), $C_{B}$ (purple), $C_{G r}$ (blue) and $C_{D i s}$ (light-blue) components (see text for further details). The inset shows the percentage of the different carbon species ( $C_{A}$ (green triangles), $C_{B}$ (purple dots), $C_{G r}$ (blue squares) and $C_{\text {Dis }}$ (light-blue diamonds), as determined by the area under the corresponding peaks. 
Figure 5. STM images and schematic models of graphene growth on clean $\mathrm{Ni}(111)$ above $500^{\circ} \mathrm{C}$. All images acquired at $520^{\circ} \mathrm{C}$ unless specified. (a) Embedded graphene island (dark stripe) in the middle of a clean $\mathrm{Ni}(111)$ terrace. (b) Final MLG layer after growth, showing regions of rotated (right) and of epitaxial (top-left) graphene $\left[V_{b}=-600 \mathrm{mV}, \mathrm{l}_{\mathrm{t}}=1 \mathrm{nA}\right]$. Inset: atomic resolution image highlighting the moiré pattern on rotated graphene $\left[\mathrm{V}_{\mathrm{b}}=-\right.$ $\left.10 \mathrm{mV}, \mathrm{I}_{\mathrm{t}}=1 \mathrm{nA}\right]$. (c) STM image at RT showing a graphene covered region grown at $520^{\circ} \mathrm{C}$ after cooling at room temperature: $\mathrm{Ni}_{2} \mathrm{C}$ islands form below rotated graphene regions $\left[\mathrm{V}_{\mathrm{b}}=-200 \mathrm{mV}, \mathrm{I}_{\mathrm{t}}=2 \mathrm{nA}\right]$. Inset: $z$ oom of the boundary between rotated graphene (right) and graphene on $\mathrm{Ni}_{2} \mathrm{C}$ (left) $\left[\mathrm{V}_{\mathrm{b}}=-100 \mathrm{mV}, \mathrm{l}_{\mathrm{t}}=2 \mathrm{nA}\right]$. (d-e) Growth mechanism (see corresponding Supplementary Movie S3). Graphene islands embedded into the Ni substrate expand by segregation of additional $\mathrm{C}$ atoms and ejection of additional $\mathrm{Ni}$ atoms. The red dot marks the position of a fixed defect on the surface. In the schematic models grey/light-blue/green/blue balls represent $\mathrm{Ni}$ /dissolved $\mathrm{C} /$ carbidic $\mathrm{C} /$ graphenic $\mathrm{C}$ atoms. $\left[\mathrm{p}\left(\mathrm{C}_{2} \mathrm{H}_{4}\right)=2 \times 10^{-7} \mathrm{mbar}\right.$, consecutive images with acquisition time $\sim 30 \mathrm{~s} /$ frame. Scanning parameters: $\left.\mathrm{V}_{\mathrm{b}}=-2 \mathrm{~V}, \mathrm{I}_{\mathrm{t}}=0.5 \mathrm{nA}\right]$

Figure 6. Graphene growth on $\mathrm{Ni}$ in case of C-contaminated subsurface. STM images during annealing at $520^{\circ} \mathrm{C}$ $(\mathrm{a}-\mathrm{c})$. Graphene seeds are already present as soon as the temperature is reached, both at step edge (a) $\left[\mathrm{V}_{\mathrm{b}}=-\right.$ $\left.600 \mathrm{mV}, \mathrm{I}_{\mathrm{t}}=0.5 \mathrm{nA}\right]$ and on a terrace $(\mathrm{b})\left[\mathrm{V}_{\mathrm{b}}=-300 \mathrm{mV}, \mathrm{I}_{\mathrm{t}}=0.8 \mathrm{nA}\right]$; (c) the complete epitaxial MLG after $\sim 1$ hour $\left[V_{b}=-400 \mathrm{mV}, \mathrm{I}_{\mathrm{t}}=0.7 \mathrm{nA}\right]$. (d) STM images of a graphene seed growth on a Ni terrace at $410^{\circ} \mathrm{C}$ without hydrocarbon exposure $\left(\mathrm{p}_{\mathrm{bg}}=2 \cdot 10^{-10} \mathrm{mbar}\right.$, see corresponding Supplementary Movie $\left.\mathrm{S} 4\right)$. The expansion occurs by $\mathrm{C}$ attachment to the edges. Time between displayed frames: $\sim 10 \mathrm{~min}$. Scanning parameters: $\mathrm{V}_{\mathrm{b}}=-600 \mathrm{mV}$, $\mathrm{I}_{\mathrm{t}}=0.4 \mathrm{nA}$. (e) Schematic model of the growth mechanism imaged in (d), grey/light-blue/purple balls represent $\mathrm{Ni}$ /dissolved C/graphenic C atoms. 
Figure 7. Time-resolved in situ low resolution XPS C1s core level spectra during annealing at $500^{\circ} \mathrm{C}$ the "carbon contaminated subsurface" $\mathrm{Ni}(111)$ single crystal [pressure during annealing $\sim 10^{-10} \mathrm{mbar}, \mathrm{p}\left(\mathrm{C}_{2} \mathrm{H}_{4}\right)=0 \mathrm{mbar}$ ]. Time $=0$ is relative to when the spectral acquisition begins. All spectra are collected in normal emission geometry at photon energies of $1253.6 \mathrm{eV}$ (surface sensitive; $\lambda_{\text {escape }} \approx 15 \AA ̊$ ) with a spectral resolution of $\sim 0.8$ $\mathrm{eV}$. Superimposed to the $\mathrm{C} 1 \mathrm{~s}$ experimental data (dots) are the fitting results (light grey) together with the Shirley background (dotted line) and the four Doniach-Šunjić $C_{A}$ (green), $C_{B}$ (purple), $C_{G r}$ (blue) and $C_{D i s}$ (lightblue) components (see text for further details). The inset shows the percentage of the different carbon species [ $C_{A}$ (green triangles), $C_{B}$ (purple dots), $C_{G r}$ (blue squares) and $C_{D i s}$ (light-blue diamonds)], as determined by the area under the corresponding peaks.

Figure 8. Schematic overview of the different graphene growth routes on $\mathrm{Ni}(111)$. 
TOC Graphics:

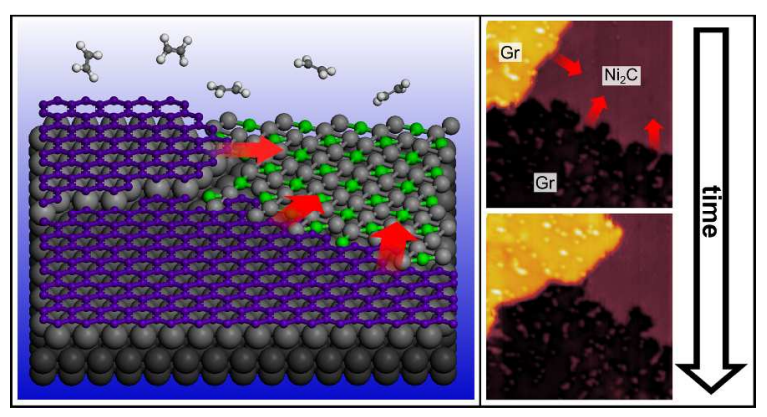

2

3

4

5

6
7

8

9

10

11

12

13

14

15

16

17

18

19

20

21

22

23

24

25

26

27

28

29

30

31

32

33

34

35

36

37

38

39

40

41

42

43

44

45

46

47

48

49

50

51

52

53

54

55

56

57

58

59

60

Page $\mathbf{2 6}$ of $\mathbf{3 1}$ 
References

1. Novoselov, K. S.; Fal'ko, V. I.; Colombo, L.; Gellert, P. R.; Schwab, M. G.; Kim, K. A Roadmap for Graphene. Nature 2012, 490, 192-200.

2. Li, X.; Cai, W.; An, J.; Kim, S.; Nah, J.; Yang, D.; Piner, R.; Velamakanni, A.; Jung, I.; Tutuc, E.; et al. LargeArea Synthesis of High-Quality and Uniform Graphene Films on Copper Foils. Science 2009, 324, 13121314.

3. Bae, S.; Kim, H.; Lee, Y.; Xu, X.; Park, J.-S.; Zheng, Y.; Balakrishnan, J.; Lei, T.; Ri Kim, H.; Song, Y. Il; et al. Roll-to-Roll Production of 30-Inch Graphene Films for Transparent Electrodes. Nat. Nanotechnol. 2010, 5, 574-578.

4. Hofmann, S.; Sharma, R.; Ducati, C.; Du, G.; Mattevi, C.; Cepek, C.; Cantoro, M.; Pisana, S.; Parvez, A.; Cervantes-Sodi, F.; et al. In Situ Observations of Catalyst Dynamics During Surface-Bound Carbon Nanotube Nucleation. Nano Lett. 2007, 7, 602-608.

5. Weatherup, R. S.; Bayer, B. C.; Blume, R.; Ducati, C.; Baehtz, C.; Schlögl, R.; Hofmann, S. In Situ Characterization of Alloy Catalysts for Low-Temperature Graphene Growth. Nano Lett. 2011, 11, 41544160 .

6. Yu, Q.; Lian, J.; Siriponglert, S.; Li, H.; Chen, Y. P.; Pei, S. S. Graphene Segregated on Ni Surfaces and Transferred to Insulators. Appl. Phys. Lett. 2008, 93, 113103.

7. Reina, A.; Thiele, S.; Jia, X.; Bhaviripudi, S.; Dresselhaus, M. S.; Schaefer, J. A.; Kong, J. Growth of LargeArea Single- and Bi-Layer Graphene by Controlled Carbon Precipitation on Polycrystalline Ni Surfaces. Nano Res. 2009, 9, 30-35.

8. Shelton, J.; Patil, H.; Blakely, J. Equilibrium Segregation of Carbon to a Nickel (111) Surface: A Surface Phase Transition. Surf. Sci. 1974, 43, 493-520.

9. Oshima, C.; Nagashima, A. Ultra-Thin Epitaxial Films of Graphite and Hexagonal Boron Nitride on Solid Surfaces. J. Phys.: Condens. Matter 1997, 9, 1-20.

10. Grüneis, A.; Kummer, K.; Vyalikh, D. V. Dynamics of Graphene Growth on a Metal Surface: a TimeDependent Photoemission Study. New J. Phys. 2009, 11, 073050.

11. Weatherup, R.; Dlubak, B.; Hofmann, S. Kinetic Control of Catalytic CVD for High Quality Graphene at Low Temperatures. ACS Nano 2012, 6, 9996-10003.

Page $\mathbf{2 7}$ of $\mathbf{3 1}$ 
12. Kidambi, P. R.; Ducati, C.; Dlubak, B.; Gardiner, D.; Weatherup, R. S.; Martin, M.-B.; Seneor, P.; Coles, H.; Hofmann, S. The Parameter Space of Graphene Chemical Vapor Deposition on Polycrystalline Cu. J. Phys. Chem. C 2012, 116, 22492-22501.

13. Li, X.; Cai, W.; Colombo, L.; Ruoff, R. S. Evolution of Graphene Growth on Ni and Cu by Carbon Isotope Labeling. Nano Lett. 2009, 9, 4268-4272.

14. Klink, C.; Stensgaard, I.; Besenbacher, F.; Lægsgaard, E. An STM Study of Carbon-Induced Structures on $\mathrm{Ni}(111)$ : Evidence for a Carbidic-Phase Clock Reconstruction. Surf. Sci. 1995, 342, 250-260.

15. Lahiri, J.; Miller, T.; Adamska, L.; Oleynik, I. I.; Batzill, M. Graphene Growth on Ni(111) by Transformation of a Surface Carbide. Nano Lett. 2011, 11, 518-22.

16. Odahara, G.; Otani, S.; Oshima, C.; Suzuki, M.; Yasue, T.; Koshikawa, T. In-Situ Observation of Graphene Growth on Ni(111). Surf. Sci. 2011, 605, 1095-1098.

17. Lahiri, J.; S Miller, T.; J Ross, A.; Adamska, L.; Oleynik, I. I.; Batzill, M. Graphene Growth and Stability at Nickel Surfaces. New J. Phys. 2011, 13, 025001.

18. Addou, R.; Dahal, A.; Sutter, P.; Batzill, M. Monolayer Graphene Growth on Ni(111) by Low Temperature Chemical Vapor Deposition. Appl. Phys. Lett. 2012, 100, 021601.

19. Jacobson, P.; Stöger, B.; Garhofer, A.; Parkinson, G. S.; Schmid, M.; Caudillo, R.; Mittendorfer, F.; Redinger, J.; Diebold, U. Nickel Carbide as a Source of Grain Rotation in Epitaxial Graphene. ACS Nano 2012, 6, 3564-72.

20. Dahal, A.; Addou, R.; Sutter, P.; Batzill, M. Graphene Monolayer Rotation on Ni(111) Facilitates Bilayer Graphene Growth. Appl. Phys. Lett. 2012, 100, 241602.

21. Weatherup, R. S.; Bayer, B. C.; Blume, R.; Baehtz, C.; Kidambi, P. R.; Fouquet, M.; Wirth, C. T.; Schlögl, R.; Hofmann, S. On the Mechanisms of Ni-Catalysed Graphene Chemical Vapour Deposition.

ChemPhysChem 2012, 13, 2544-2549.

22. Hofmann, S.; Blume, R.; Wirth, C. T.; Cantoro, M.; Sharma, R.; Ducati, C.; Hävecker, M.; Zafeiratos, S.; Schnoerch, P.; Oestereich, A.; et al. State of Transition Metal Catalysts During Carbon Nanotube Growth. J. Phys. Chem. C 2009, 113, 1648-1656.

23. Wirth, C. T.; Bayer, B. C.; Gamalski, A. D.; Esconjauregui, S.; Weatherup, R. S.; Ducati, C.; Baehtz, C.; Robertson, J.; Hofmann, S. The Phase of Iron Catalyst Nanoparticles During Carbon Nanotube Growth. Chem. Mater. 2012, 24, 4633-4640. 
24. Dong, G. C.; Baarle, D. W. van; Rost, M. J.; Frenken, J. W. M. Graphene Formation on Metal Surfaces Investigated by In-Situ Scanning Tunneling Microscopy. New J. Phys. 2012, 14, 053033.

25. Ehrlich, G. Direct Observations of the Surface Diffusion of Atoms and Clusters. Surf. Sci. 1991, 246, 1-12.

26. Jacobson, P.; Stöger, B.; Garhofer, A.; Parkinson, G. S.; Schmid, M.; Caudillo, R.; Mittendorfer, F.; Redinger, J.; Diebold, U. Disorder and Defect Healing in Graphene on Ni (111). J. Phys. Chem. Lett. 2011, 3, 136-139.

27. Zhao, W.; Kozlov, S. M.; Höfert, O.; Gotterbarm, K.; Lorenz, M. P. A.; Viñes, F.; Papp, C.; Görling, A.; Steinrück, H.-P. Graphene on Ni (111): Coexistence of Different Surface Structures. J. Phys. Chem. Lett. 2011, 2, 759-764.

28. Dzemiantsova, L. V.; Karolak, M.; Lofink, F.; Kubetzka, A.; Sachs, B.; Bergmann, K. von; Hankemeier, S.; Wehling, T. O.; Frömter, R.; Oepen, H. P.; et al. Multiscale Magnetic Study of Ni(111) and Graphene on Ni(111). Phys. Rev. B 2011, 84, 205431.

29. Karpan, V. M.; Khomyakov, P. A.; Starikov, A. A.; Giovannetti, G.; Zwierzycki, M.; Talanana, M.; Brocks, G.; Brink, J. van den; Kelly, P. J. Theoretical Prediction of Perfect Spin Filtering at Interfaces Between Close-Packed Surfaces of Ni or Co and Graphite or Graphene. Phys. Rev. B 2008, 78, 195419.

30. Vang, R. T.; Honkala, K.; Dahl, S.; Vestergaard, E. K.; Schnadt, J.; Lægsgaard, E.; Clausen, B. S.; Nørskov, J. K.; Besenbacher, F. Ethylene Dissociation on Flat and Stepped Ni(111): A Combined STM and DFT Study. Surf. Sci. 2006, 600, 66-77.

31. Morar, J.; Himpsel, F.; Hollinger, G. C1s Excitation Studies of Diamond (111). I. Surface Core Levels. Phys. Rev. B 1986, 33, 1340-1345.

32. Webb, M. J.; Palmgren, P.; Pal, P.; Karis, O.; Grennberg, H. A Simple Method to Produce Almost Perfect Graphene on Highly Oriented Pyrolytic Graphite. Carbon 2011, 49, 3242-3249.

33. Lander, J. J.; Kern, H. E.; Beach, A. L. Solubility and Diffusion Coefficient of Carbon in Nickel: Reaction Rates of Nickel-Carbon Alloys with Barium Oxide. J. Appl. Phys. 1952, 23, 1305-1309.

34. Díaz, J.; Paolicelli, G.; Ferrer, S.; Comin, F. Separation of the sp3 and sp2 Components in the C1s Photoemission Spectra of Amorphous Carbon Films. Phys. Rev. B 1996, 54, 8064-8069.

35. Varykhalov, A.; Sánchez-Barriga, J.; Shikin, A.; Biswas, C.; Vescovo, E.; Rybkin, A.; Marchenko, D.; Rader, O. Electronic and Magnetic Properties of Quasifreestanding Graphene on Ni. Phys. Rev. Lett. 2008, 101, 157601. 
36. Tanaka, K.; Hirano, H. Isolation of Intermediate Compounds of Catalytic Reactions on Single Crystal Surfaces. Catal. Lett. 1992, 12, 1-6.

37. Stierle, A.; Molenbroek, A. Novel In Situ Probes for Nanocatalysis. MRS bulletin 2007, 32, 1001-1009.

38. Kozlov, S.; Viñes, F.; Görling, A. Bonding Mechanisms of Graphene on Metal Surfaces. J. Phys. Chem. C 2012, 116, 7360-7366.

39. Starodub, E.; Maier, S.; Stass, I.; Bartelt, N. C.; Feibelman, P. J.; Salmeron, M.; McCarty, K. F. Graphene Growth by Metal Etching on Ru(0001). Phys. Rev. B 2009, 80, 235422.

40. Günther, S.; Dänhardt, S.; Wang, B.; Bocquet, M.-L.; Schmitt, S.; Wintterlin, J. Single Terrace Growth of Graphene on a Metal Surface. Nano Lett. 2011, 11, 1895-1900.

41. Arnoult, W.; McLellan, R. The Solubility of Carbon in Rhodium Ruthenium, Iridium and Rhenium. Scr. Metall. Mater. 1972, 6, 1013-1018.

42. Lacovig, P.; Pozzo, M.; Alfè, D.; Vilmercati, P.; Baraldi, A.; Lizzit, S. Growth of Dome-Shaped Carbon Nanoislands on $\operatorname{Ir}(111)$ : The Intermediate Between Carbidic Clusters and Quasi-Free-Standing Graphene. Phys. Rev. Lett. 2009, 103, 166101.

43. Miniussi, E.; Pozzo, M.; Baraldi, A.; Vesselli, E.; Zhan, R. R.; Comelli, G.; Menteş, T. O.; Niño, M. A.; Locatelli, A.; Lizzit, S.; et al. Thermal Stability of Corrugated Epitaxial Graphene Grown on Re(0001). Phys. Rev. Lett. 2011, 106, 216101.

44. Mittendorfer, F.; Garhofer, A.; Redinger, J.; Klimeš, J.; Harl, J.; Kresse, G. Graphene on Ni(111): Strong Interaction and Weak Adsorption. Phys. Rev. B 2011, 84, 201401.

45. Helveg, S.; López-Cartes, C.; Sehested, J.; Hansen, P. L.; Clausen, B. S.; Rostrup-Nielsen, J. R.; AbildPedersen, F.; Nørskov, J. K. Atomic-Scale Imaging of Carbon Nanofibre Growth. Nature 2004, 427, 426429.

46. Zhang, Y.; Gao, T.; Xie, S.; Dai, B.; Fu, L.; Gao, Y.; Chen, Y.; Liu, M.; Liu, Z. Different Growth Behaviors of Ambient Pressure Chemical Vapor Deposition Graphene on $\mathrm{Ni}(111)$ and Ni Films: A Scanning Tunneling Microscopy Study. Nano Res. 2012, 5, 402-411.

47. Sutter, E.; Albrecht, P.; Sutter, P. Graphene Growth on Polycrystalline Ru Thin Films. Appl. Phys. Lett. 2009, 95, 133109.

48. Africh, C.; Esch, F.; Comelli, G.; Rosei, R. Dynamics of the O Induced Reconstruction of the Rh(110) Surface: A Scanning Tunnelling Microscopy Study. J. Chem. Phys. 2001, 115, 477-481.

Page 30 of 31 
1

2

3

4

5

6

7

8

9

10

11

12

13

14

15

16

17

18

19

20

21

22

23

24

25

26

27

28

29

30

31

32

33

34

35

36

37

38

39

40

41

42

43

44

45

46

47

48

49

50

51

52

53

54

55

56

57

58

59

60
49. Bluhm, H.; Hävecker, M.; Knop-gericke, A.; Kiskinova, M.; Schlögl, R.; Salmeron, M. In Situ X-Ray Photoelectron Studies of Gas-Solid Interfaces at Near-Ambient Conditions. MRS Bulletin 2007, 32, 10221030. 


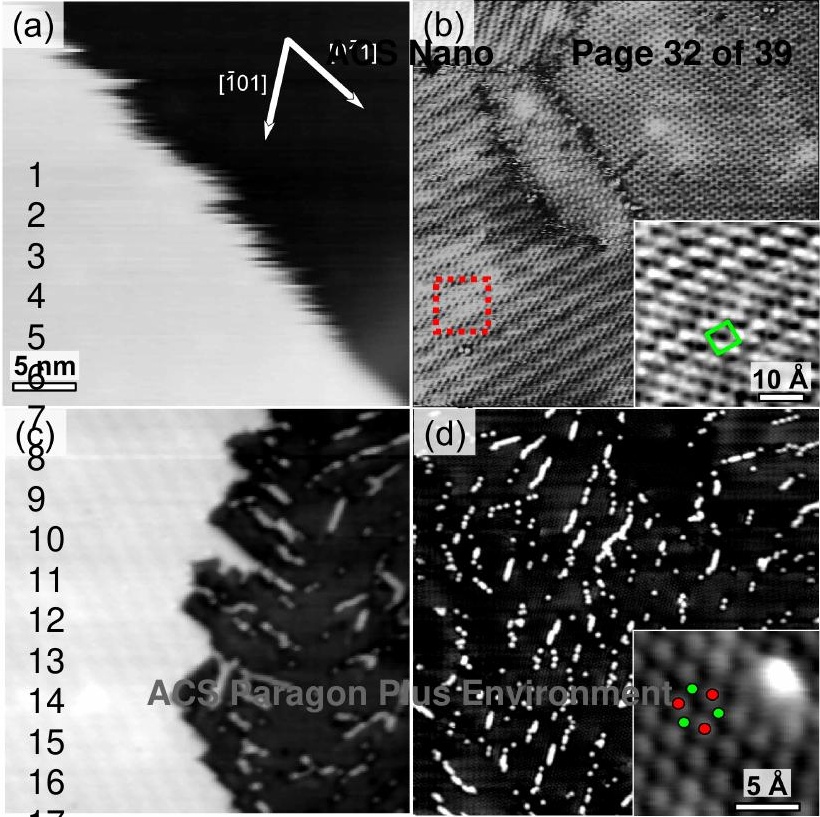


(a)

Page 33 of 39

1

2

$3 \mathrm{Ni}_{2} \mathrm{C}$

4

5

6

7

(8) $\mathrm{Ni}_{2} \mathrm{C} \quad \mathrm{Gr}$

9

1

12

14

15

( 96

17

18

19

20

21

22

23

$\frac{2}{2}$



$\mathrm{Ni}_{2} \mathrm{C}$

2 3
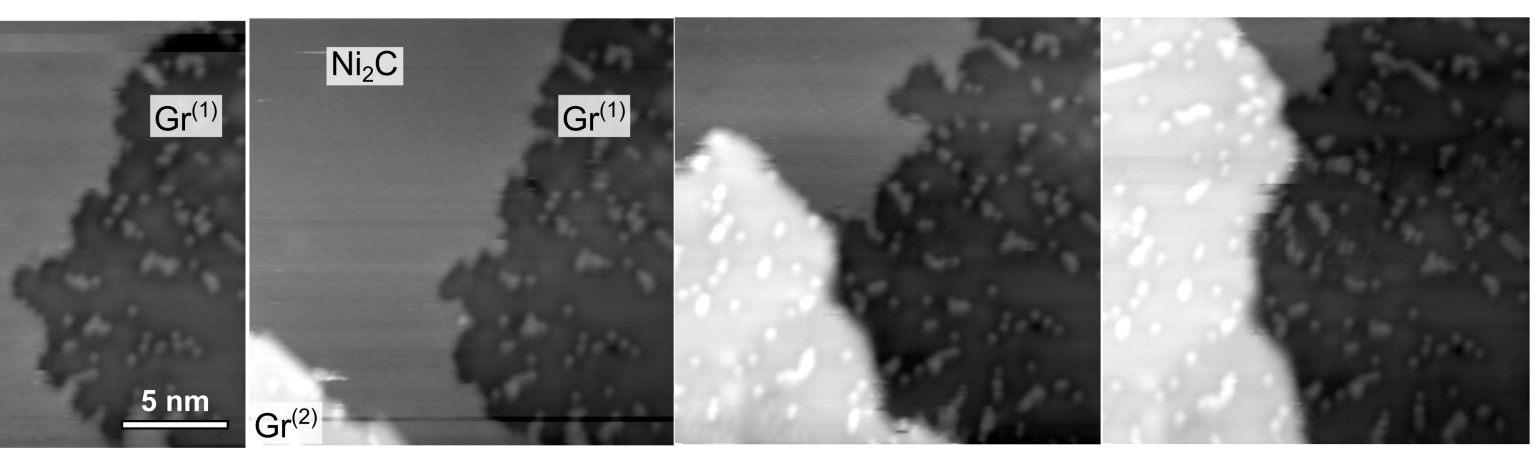

\section{$\mathrm{Gr}^{(2)}$}

$\mathrm{Ni}_{2} \mathrm{C}$

ACS Peragon-PIns Envirgment 


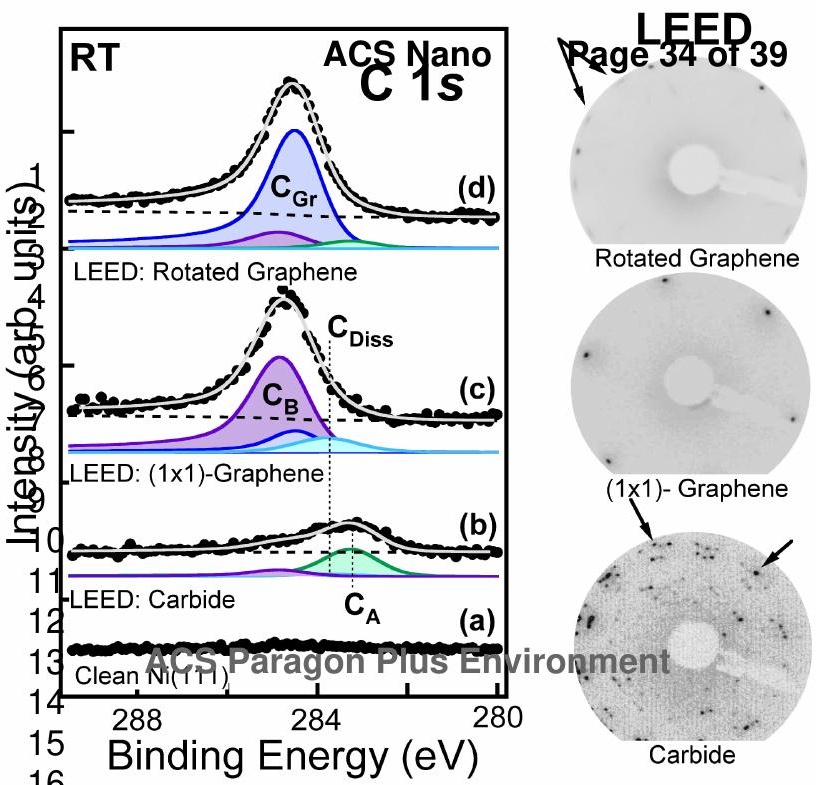


(a)

(b)

hechlang

(c)

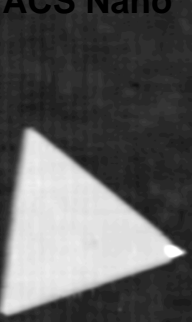

0
0
0

10

(d) 1

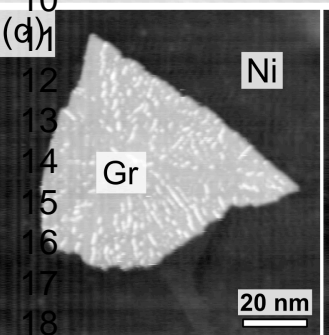

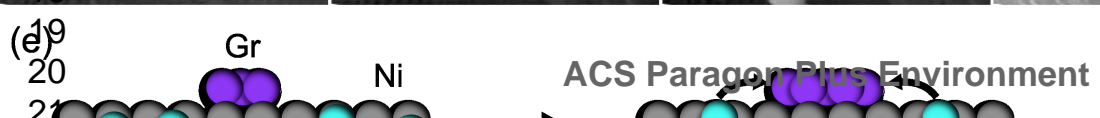

$10 \mathrm{~nm}$

$20 \mathrm{~nm}$

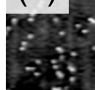

(n)

8.28 $z:$

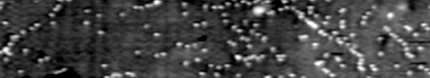

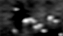

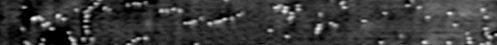

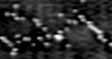

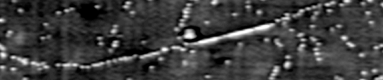

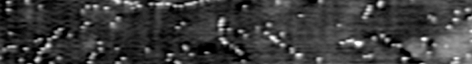

to.?

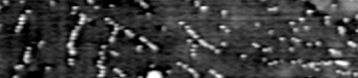

$3 \times 3 \times 3$

$10 \mathrm{~nm}$
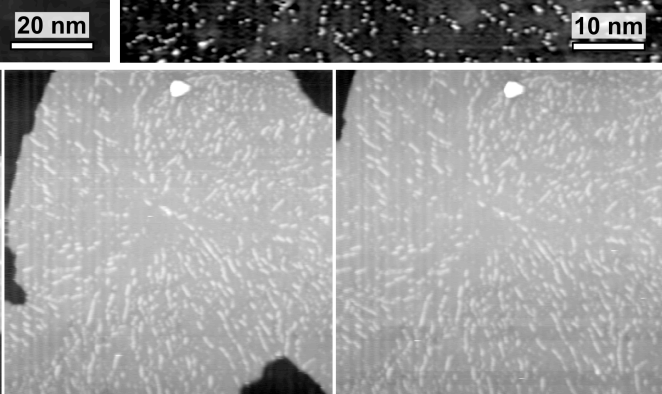

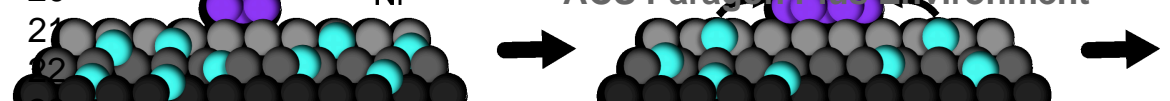

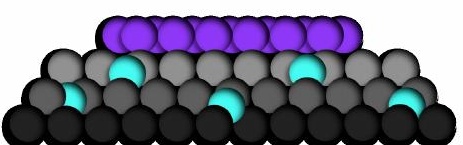




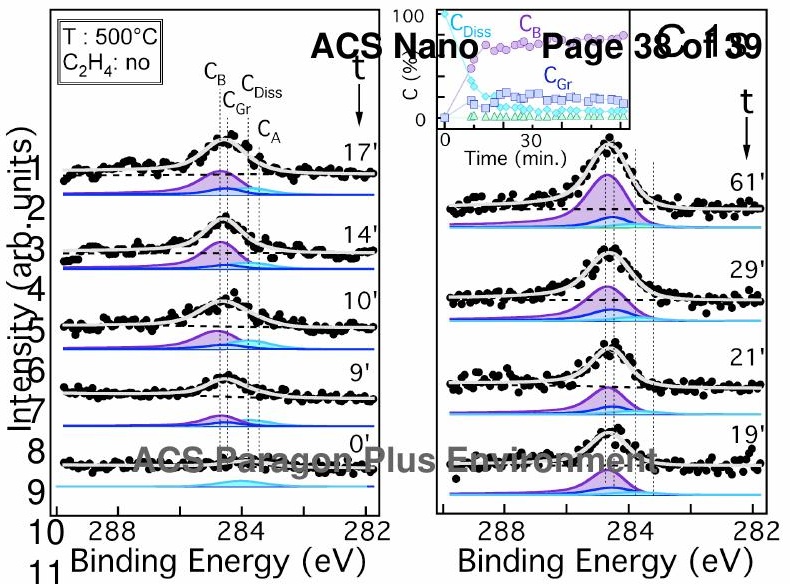


Page 39 of 39

ACS Nano

RT Heating

Growth Temperature

Cooling

\section{RT}

With $\mathrm{C}_{\mathrm{x}} \mathrm{H}_{\mathrm{y}}$ exposure

2

3

4

5

6

7

8

Gean Subsurface कर्वófón

12

13

14

15

16

17

18

19

20 Contaminated

21 Subsurface

23
24

?र्विद्वि

24

25

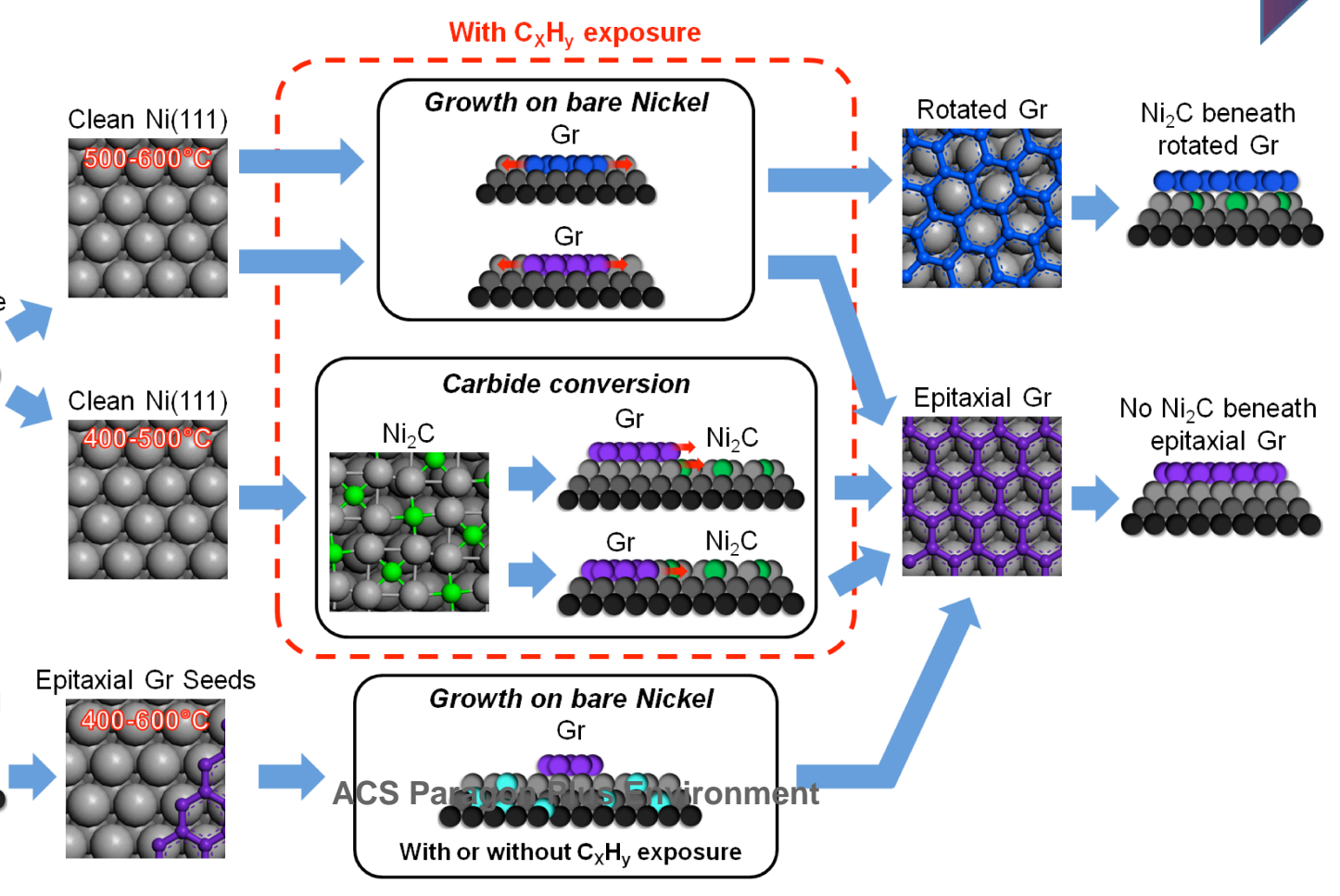

